\title{
A BIOMECHANICAL INVESTIGATION OF THE HIND LIMB OF THE PLIOPOTAMYS - ONDATRA LINEAGE
}

FLINT, Mary E.T., Dept. of Biological Sciences, Idaho State University, Campus Box 8007, Pocatello, ID 83209, U.S.A.

A fundamental theme of paleobiology is relating form to function in a historical context. The modern North American muskrat (Ondatra zibethicus) has a well-documented fossil history, represented by a single lineage spanning some 3.75 million years from Pliopotamys minor. This lineage has been based on character trends of muskrat dentitions including molar size, number of triangles and roots, the height of dentine tracts on the first molar, and the development of cementum in the reentrant angles. Modern muskrats are highly adapted to an aquatic life, but the degree to which fossil muskrat taxa were aquatically adapted has not been previously studied. The usual assumption that all members of the Pliopotamys Ondatra lineage were extremely aquatic is based on modern muskrat habitats and on the frequent occurrence of fossil forms in fluvial/lacustrine depositional environments rather than on functional morphology.

Using biplanar $x$-rays and engineering beam theory, $I$ examined the cross-sectional properties (CA, $J / 2)$ of femora and tibiae in the Pliopotamys - Ondatra lineage to determine resistance to axial compression, bending rigidity, and torsional rigidity. Cortical cross-sectional area (CA) is proportional to axial compression and mean moments of inertia $(\mathrm{J} / 2)$ are proportional to bending resistance and torsional rigidity of a long bone cross-section. Comparative cross-sectional properties were also calculated for the femora and tibiae of Neofiber alleni (Florida water rat), a semi-aquatic rodent that is more of a wader than a swimmer. Differential values of these properties are taken to reflect differences in swimming efficiency between the two extant species. Femoral and tibial diaphyses of Ondatra are better able to withstand mechanical stresses compared with those of Neofiber. Comparison of cross-sectional properties of these bones within members of the Pliopotamys - Ondatra lineage indicate temporal trends of increasing resistance to bending, torsion, and axial loads which $I$ interpret as reflections of adaptational changes to greater swimming efficiency. The resistance to bending, torsion and axial loading in earliest members of this lineage is very similar to values calculated for extant Neofiber alleni while later members show increasing similarities to extant Ondatra zibethicus. 